\title{
A Educação ambiental como exercício de poder e resistência
}

\author{
Rodrigo Barchi \\ Doutorando em Educação UNICAMP- Professor-Coordenador do Curso de Geografia da Universidade de Sorocaba- \\ Universidade Estadual de Campinas - São Paulo- Brasil
}

\begin{abstract}
Resumo
A partir dos conceitos de poder e resistência, desenvolvidos por Michel Foucault - o poder, como algo que se exerce, vem de baixo, e é capturado pelo Estado; e a resistência, como o combate aos efeitos desse poder - a presente pesquisa intenciona buscar e debater algumas ressonâncias do amplo processo de institucionalização pelo qual atravessa a educação ambiental no Brasil, e a conseqüente transformação de suas concepções teóricas e práticas em leis e normas. Intenciona-se discutir a o funcionamento da educação ambiental como um exercício de poder, identificando seus mecanismos, ferramentas e dispositivos que a podem constituir como uma forma de sujeição e dominação ao que Foucault chamou de governamentalidade; e também de buscar referenciais teóricos que possibilitem potencializar as relações entre meio ambiente e educação como múltiplas maneiras de resistência às possíveis "docilizações" e uniformizações de conduta e modos de pensar promovidas por perspectivas hegemônicas institucionalizadas.
\end{abstract}

Palavras-chave: Educação ambiental; poder; resistência

\begin{abstract}
From the concepts of power and resistance, developed by Michel Foucault - the power, as something that prosecutes, comes from below, and it is captured by the State; and the resistance, as the combating to the effects of this power - this article intends to discuss some resonances of the wide institutionalization process through which passes the environmental education in Brazil, and the consequent transformation of its theoretical concepts and practices in laws and regulations. It is discussed the possibility of understanding the environmental education as an exercise of power, which is considered as another form of bondage and domination maintained by the governmentality, and on the other hand, to understand it as different ways to resist possible "docilization" and standarlization of conduct and ways of thinking promoted by institutionalized hegemonic perspectives.
\end{abstract}

Keywords: Environmental education, power, resistance 
Necessidade de dominar: tu que também vens encontrar, com todos seus encantos, os puros e os solitários, tu que sobes a alturas que se bastam a si mesmas, ardentes como um amor que vem pintar os horizontes terrestres perspectivas sedutoras e felicidades púrpuras.

Nietzsche

\section{A INSTITUCIONALIZAÇÃO DA EDUCA- ÇÃO AMBIENTAL NO BRASIL}

A educação ambiental no Brasil atravessa um amplo processo de institucionalização e regulamentação de suas concepções teóricas, instrumentalizações técnicas, e de suas formas de ação e prática. Ela encontra-se, no Brasil, amparada e sustentada por um complexo e intrincado aparato documental, técnico e judiciário, que estabelece sua obrigatoriedade como uma das possíveis formas de transformação social e ecológica de uma situação de crise na qual todos os países do globo, de forma mais ou menos intensa, atravessam.

Esta obrigatoriedade está bem definida no artigo 11 da Lei de Política Nacional de Educação Ambiental, de 1999, principalmente no que diz respeito à sua implantação na educação formal:

Artigo 11 - A dimensão ambiental deve constar nos currículos de formação dos professores em todos os níveis e em todas as disciplinas.

Parágrafo único. Os professores em atividade devem receber formação complementar em suas áreas de atuação, com o propósito de atender adequadamente ao cumprimento dos princípios e objetivos da Política Nacional de Educação Ambiental. (BRASIL, 1999)

O marco inicial dessa institucionalização pode ser considerado a criação da SEMA, em 1973 - então comandada por Paulo Nogueira-Neto - tendo na educação ambiental um de seus eixos de atuação, possibilitando a divulgação e a contribuição do povo brasileiro para com os cuidados com o meio ambiente.

Entre os mais significativos eventos, estão: o estabelecimento da Lei de Política de Meio Ambiente de 1981; a obrigatoriedade pela Constituição de 1988; a adesão ao Tratado de Educação Ambiental para as Sociedades Sustentáveis e Res- ponsabilidade Global (estabelecido pelo Fórum Global de 1992); a implementação do tema Meio Ambiente nos Parâmetros Curriculares Nacionais na segunda metade dos anos 90 (como forma de Temas Transversais); a instituição de uma Política Nacional de Educação Ambiental, em 1999; e a criação de Órgãos Gestores de Educação Ambiental e de um Programa Nacional próprio, já na primeira década do século XXI.

Talvez seja devido a essa ampla institucionalização que a história da Institucionalização da Educação Ambiental brasileira geralmente seja confundida com a própria história da Educação Ambiental no Brasil. Um exemplo é o próprio documento do Programa Nacional de Educação Ambiental (Pronea, 2006), que ao registrar essa história, o faz como um simples processo de institucionalização.

A exceção é somente uma pequena referência de menos de um parágrafo, no que diz respeito ao próprio surgimento da EA no Brasil. É quando são citados "artigos de brasileiros ilustres" no século XIX, um persistente movimento conservacionista e da emergência de um ambientalismo nos anos 70 ligado às lutas pelas liberdades democráticas (no período do governo militar), que se manifestam em ações isoladas de professores, escolas e alunos (BRASIL, 2006, p. 21.) . No restante, várias páginas são ocupadas com o registro de criações de secretarias, departamentos, realização de conferências organizadas e/ ou apoiadas pelo governo federal, e a instituição de leis e políticas públicas.

Por um lado, essa maciça e intensa institucionalização tem como argumentos o atendimento às reivindicações das diferentes perspectivas ecológicas que sempre viram na educação uma das mais eficientes ferramentas para possibilitar a transformação necessária dos modos de fazer e pensar dos humanos, que impedisse a hecatombe ecológica do planeta.

Se os pensamentos ecológicos são aqueles que perceberam a necessidade de mudar o rumo das atitudes humanas, uma educação baseada em seus pressupostos, tornada oficial, é vista como um grande passo para a realização de um futuro mais ecológico. Cabe ressaltar aqui uma das mais interessantes premissas da Educação Ambiental na qual "o futuro será verde, ou simplesmente não será".

Por outro lado, essa institucionalização e regulamentação ocorrem em um contexto no qual as formas de se fazer e pensar na EA estão imersas no âmbito de um Estado que somente permite aquilo que não ameace sua dominação, 
sua soberania e seu poder. É necessário, portanto, que na própria EA então estabelecida como política oficial se faça uma classificação, hierarquização e exclusão/inclusão das perspectivas e saberes que lhe serão úteis em sua perpetuação.

Mas se era justamente a centralização do poder no Estado em sua aliança com o capital é que promove a destruição do planeta, a implantação de uma EA por esse mesmo Estado é a responsável por sua banalização e destruição? Ou a EA será justamente mais um dos dispositivos do Estado para a continuidade do seu poder, a partir de agora, sob uma determinada perspectiva ecológica que não seja discrepante dos interesses do capital?

Pode haver uma EA que funcione de outra forma, alheias, fora, marginal ou menor à que foi estabelecida? Onde elas funcionam como exercício de poder e onde funciona como exercício de resistência? Ela pode manter sua radicalidade contestatória e reivindicativa estando já cristalizada em regulamentações?

\section{PODER}

Para ser possível levantar algumas possibilidades de discutir sobre as questões acima, deve-se levar em consideração que, de acordo com Foucault (1988), a soberania do estado, a forma da lei ou a unidade global de uma dominação são nada mais que as formas terminais do poder. Ele sugere a seguinte compreensão do poder:

... Primeiro, como a multiplicidade de correlações de força imanentes ao domínio onde se exercem e constitutivas de sua organização; o jogo que através de lutas e enfrentamentos incessantes as transforma, reforça, inverte; os apoios que estas relações encontram umas nas outras, formando cadeias ou sistemas ou, ao contrário, as defasagens e contradições que as isolam entre si; enfim, as estratégias em que se originam e cujo esboço geral ou cristalização institucional toma corpo nos aparelhos estatais, na formulação das leis, nas hegemonias sociais. (Foucault, 1988, p. 88-89)

Ele não compreendia o poder como o próprio conjunto de instituições e aparelhos garantidores da sujeição dos cidadãos em um Estado determinado, ou ainda como um sistema geral de dominação exercida por um elemento ou grupo sobre outro, cuja influência se dá em todas as esferas do corpo social. O poder, para Foucault, é algo que se exerce, mais do que se possui:

O poder está em toda a parte; não porque englobe tudo, e sim, porque provém de todos os lugares. E "o" poder, no que tem de permanente, repetitivo, de inerte, e auto-reprodutor, é apenas efeito de conjunto, esboçado a partir de todas essas modalidades, encadeamento que se apóia em cada uma delas e, em troca, procura fixá-las. (Foucault, 1988, p. 89)

O poder vem de baixo, com o surgimento de uma linha de força geral que atravessa os afrontamentos e os ligamentos entre si, em cujo processo homogeneizar, alinhar, colocar em série e fazê-los convergir, em um processo que podemos chamar justamente de homogeneização.

Para estudar a microfísica desse exercício de poder - o qual Foucault (FOUCAULT, 1988, p. 89.) também chamava de "situação estratégica complexa numa sociedade determinada" - era sugerido que não fossem observados os efeitos de poder como uma apropriação, e sim, como disposições, manobras, táticas, técnicas e funcionamentos.

Atentava ele que não era a partir do direito como uma legitimidade a ser fixada, ou a partir da soberania, que era preciso observar a questão do poder, mas sim, a dominação e a sujeição, para o âmbito dos operadores materiais, das formas de sujeição, as conexões e utilizações de sistemas locais para essa sujeição. Ou seja, analisar o poder a partir das técnicas e táticas de dominação.(FOUCAULT, 1999, p. 40. ) É possível pensar ainda no que Deleuze afirma, ao analisar a obra de Foucault, do exercício do poder aparecer como um afeto, como a força que se define por seu poder de afetar outras forças, sendo essas relações de poder como diferenciais que determinam as singularidades, ou seja, os afetos. (DELEUZE, 2006, p. 79)

Ao observar a perspectiva de poder de Foucault, Deleuze sugere que as instituições como o Estado, a família, a religião, a produção, o mercado, e até a arte e a moral, não são nem as fontes, nem a essência do poder:

São práticas, mecanismos operatórios que não explicam o poder, já que supõe as relações e se contentam em fixá-las sob uma função reprodutora e não reprodutora. (Deleuze, 2006, p. 83)

De acordo ainda com Deleuze, o que 
ocorreu é que o Estado - assim como as outras instituições - acabou capturando muitas relações de poder. Isso é devido uma operação de estatização contínua que se produziu nas ordens sexual, familiar, econômica, judiciária e - o que mais interessa ao falar de Educação Ambiental - na ordem pedagógica, visando uma integração global . (Deleuze, 2006, p. 83)

Para entender esse processo, é necessário que se compreenda o conceito de biopoder. Foucault afirmava o poder que prevalecia até o século XVI era o poder soberano, que se dava como um poder de morte e um direito de apreensão das coisas, dos tempos, dos corpos e da vida, se apoderando dessa última para suprimi-la, onde a morte era o ponto onde se brilhava a soberania, o absoluto poder do soberano . (FOUCAULT, 1988, p. 128) Aquilo que passou a ser exercido do século XVII em diante pode ser chamado de biopoder, ou seja, aquele capaz de causar a vida, cuja tarefa era gerir a vida. É sobre a vida é que deve se exercer o poder.

Esse biopoder se desenvolveu a partir do século XVII em duas formas principais. A primeira, chamada por Foucault de anatomopolitica do corpo humano, era um conjunto de técnicas que, centradas no corpo individual, promoviam violência, separação, alinhamento e colocação em série, caracterizando assim, as disciplinas. Era a produção dos corpos dóceis e úteis, além do próprio adestramento, a partir da constante vigilância, avaliação e punição ${ }^{1}$.

A sujeição dos corpos foi "elemento indispensável ao desenvolvimento do capitalismo, que só pode ser garantido à custa da inserção controlada dos corpos e dos aparelhos de produção" (FOUCAULT, 1988, p. 132). A escola, o hospital, o quartel e a prisão são entendidos, por Foucault (1987, p. 117-118) como espaços privilegiados dessa ação, onde a descoberta do corpo ocorre como objeto e alvo do poder, e as disciplinas são como formas de gerar dominação.

A outra forma, que se desenvolve a partir do fim do século XVII e durante o século XVIII não se dirige mais ao corpo individual, mas sim ao chamado homem-espécie, ou seja, a população em geral. Aquilo que Foucault chamou de biopolítica se dirigia à multiplicidade dos humanos à massa global, a processos preocupados com a "proliferação, os nascimentos e a mortalidade, o nível de saúde, a duração da vida, a longevidade". (FOUCAULT, 1988, p. 132) Ela lida com a popu-

1 Em "Vigiar e Punir", Foucault desenvolve sua análise a partir da dinâmica da utilização do panóptico de J. Bentham. lação como um problema político e biológico, intervindo nos fenômenos com que eles tem de mais global. Na biopolítica:

Não se trata, por conseguinte, em absoluto, de considerar o indivíduo no nível do detalhe, mas, pelo contrário, mediante mecanismos globais, de agir de tal maneira que se obtenham estados globais de equilíbrio, de regularidade; em resumo, de levar em conta a vida, os processos biológicos do homem-espécie e de assegurar sobre eles não uma disciplina, mas uma regulamentação (Foucault, 1999, p. 294)

Por um lado, existem duas séries: a primeira é o corpo-organismo-disciplina-instituições, como o caso da polícia, dos hospitais, dos hospícios, dos quartéis, das escolas. A segunda, a série população-processos biológicos-mecanismos regulamentadores-Estado, ou seja, a bioregulamentação da vida pela forma-Estado. Mas de nenhuma forma, estas duas séries, esses dois conjuntos de mecanismos estão opostos e/ou no mesmo nível, mas não se excluem e se articulam.(FOUCAULT, 1999, p. 298-299)

Dois exemplos que Foucault cita brevemente podem ser utilizados aqui para fazer a devida conexão sobre a utilização da educação ambiental como exercício do poder.

Em primeiro lugar é a questão das cidades, as quais articulam o controle disciplinar sobre os corpos das famílias (cada uma em uma casa) e dos indivíduos (cada um em um cômodo), num claro exemplo de microfísica do poder exercido no arranjo espacial urbano. Ao mesmo tempo, encontramos mecanismos regulamentadores que instalam políticas públicas de higiene, saúde, educação e sexualidade.

Aliás, a própria sexualidade é utilizada por Foucault para explicitar a articulação entre as duas séries de biopoder, a biopolítica e a anatomopolítica. Ela está na encruzilhada do corpo e da população. Ao mesmo tempo em que a masturbação excessiva da criança vai lhe ser prejudicial e lhe adoentar durante toda a vida, sendo necessário um controle disciplinar do corpo, por outro lado, a postura devassa de um indivíduo pode levar problemas a todo o corpo da população, sendo necessário, portanto, a regulamentação e a normalização das condutas sexuais da população:

...nunca a disciplina foi tão importante e tão valorizada quanto a partir do momento em que se procurou gerir a população. $\mathrm{E}$ 
gerir a população não queria dizer simplesmente gerir a massa coletiva dos fenômenos globais. Gerir a população significa geri-la em profundamente, minuciosamente, no detalhe. (Foucault, 1979, p. 291)

Gerir, governar a população, é um tipo de poder que levou ao desenvolvimento de diversos aparatos do próprio governo e um conjunto de saberes. Deleuze lembra que Chatelet desenvolveu a idéia de "poder como exercício e saber como regulamento" (DELEUZE, op. cit., p. 82 )para compreender essa dinâmica. Foucault afirma que o Estado precisou desenvolver essa governamentalidade, tornando as técnicas de governo a questão política principal e o espaço real da luta política:

Se o Estado é hoje o que é, é graças a esta governamentalidade, ao mesmo tempo interior e exterior ao Estado. São as táticas de governo que permitem definir, a cada instante o que deve ou não competir ao Estado, o que é público ou privado, ou que é ou não estatal, etc. Portanto o Estado, em sua sobrevivência e em seus limites, deve ser compreendido a partir das táticas gerais da governamentalidade. (Foucault, 1979, p. 292)

Como a educação ambiental se insere nessa forma específica e complexa de poder que é a governamentalidade, que tem como alvo a população, o seu disciplinamento e o seu controle, a partir de mecanismos de adestramento e segurança?

\section{EDUCAÇÃO AMBIENTAL COMO EXER- CÍCIO DE PODER}

A concepção de educação ambiental oficializada na Lei 9785, de 27 de abril de 1999, que institui a Política Nacional de Educação Ambiental, mostra a preocupação com a qualidade de vida e a sustentabilidade e, que para preservá-las, são necessários processos educativos que agirão tanto no corpo do indivíduo quanto na coletividade:

Art. 1 - Entendem-se por Educação Ambiental os processos por meio dos quais o indivíduo e a coletividade constroem valores sociais, conhecimentos, habilidades, atitudes e competências voltadas para a conservação do meio ambiente, bem de uso comum do povo, essencial à sadia qualidade de vida e sua sustentabilidade.
(BRASIL, 1999)

Por um lado, a educação ambiental age diretamente no corpo individual, promovendo um processo de disciplinamento que construa habilidades, atitudes e competências, tendo como o regulamento desse mecanismo os chamados conhecimentos ambientais. É a anatomopolítica que fará com que cada indivíduo se torne um agente e um instrumento útil e obediente à determinada concepção de ambiente instituída pela governamentalidade. Essas habilidades, competências e atitudes são formadas a partir da convergência e universalidade devidamente instauradas pela lei. São elas as responsáveis - e modelos a ser seguidos - pela qualidade da vida e sua manutenção.

A educação ambiental como exercício de poder no corpo dos indivíduos também pode ser observada quando ela sugere-se desenvolvida no ambiente escolar, cuja ação, tanto quanto direcionada ao corpo dos alunos, estará direcionada à própria formação dos professores. De acordo com o artigo 11 da Política Nacional de Educação, já citada anteriormente, os professores devem receber uma formação complementar em Meio Ambiente, sejam eles de qualquer nível ou área.

Se não receber os devidos conhecimentos sobre o meio ambiente, de acordo com a definição e os conceitos que estão determinados, ele não poderá cumprir a Política Nacional, não será considerado um educador ambiental, não poderá contribuir para com a conservação, a sustentabilidade e a qualidade de vida. Não poderá exercer um papel pré-definido como um educador e sua condição de não estar devidamente formado com esses conhecimentos ameaçará todo o processo pedagógico que se quer ecologicamente comprometido.

É uma educação ambiental como exercício de poder controlador e regulamentador, ou seja, como biopolítica, já que o meio ambiente, sendo um bem comum ao povo, deverá ser o eixo norteador, o valor instituído, que levará á futura qualidade de vida desejada pela utopia da sustentabilidade. $\mathrm{O}$ Estado, em seu exercício de governamentalidade, age como instituição disciplinadora, age sobre o a prática cotidiana do educador em sua singularidade, assim como em toda a esfera da sociedade:

Art. 13. Entende-se por educação ambiental não forma, as ações e prátias educativas voltadas à sensibilização da coletividade sobre as questões ambientais e à sua organização e participação na defesa da qualidade do meio ambiente. (BRASIL, 1999) 
Ao atuar como articulador entre as mais diferentes esferas da sociedade - meios de comunicação de massa, organizações não-governamentais, empresas públicas e privadas, populações tradicionais, agricultores, ecoturismo - a governamentalidade usa a educação ambiental como uma espécie de dispositivo uniformizador de condutas, as quais deverão cumprir suas atividades e articulações de acordo com a noção de meio ambiente da Política Pública.

O esforço em tornar a educação ambiental uma prática normalizadora e controladora - ou seja, biopolítica - pode ser observada em diversos pontos dos documentos do Programa Nacional de Educação Ambiental (PRONEA 2006), no que diz respeito aos objetivos da Educação Ambiental, dos quais três merecem destaque:

- Estimular as empresas, entidades de classe, instituições políticas e privadas a desenvolverem programas destinados à capacitação de trabalhadores, visando a melhoria e ao controle efetivo sobre o meio ambiente de trabalho, bem como as repercussões do processo produtivo no meio ambiente. -Difundir a legislação ambiental, por intermédio de programas, projetos e ações da Educação Ambiental.

-Produzir e aplicar instrumentos de acompanhamento, monitoramento e avaliação das ações do PRONEA, considerando a coerência com suas diretrizes. (grifos meus) (BRASIL, 2006, p. 40-41)

É o corpo do trabalhador que deve ser capacitado, treinado, adestrado, "docilizado" e utilizado para a melhoria e o controle sobre o ambiente de trabalho. É o ajustamento individual que possibilitará o devido controle e regulamentação a partir de determinada concepção de meio ambiente, ou seja, aquela que está devidamente registrada e oficializada pela legislação ambiental, que deverá ser difundida a partir dos programas, projetos e ações da Educação Ambiental. Ações que serão devidamente acompanhadas, monitoradas e avaliadas por instrumentos e dispositivos, que dirão se tal ação será realmente uma ação válida sob essa perspectiva de educação ambiental.

Para Passetti, vivemos, mais do que um período de dominância da biopolítica, um período de instauração da ecopolítica, que pode ser entendida como: ...uma ocupação pela qual os Estados vão organizando a centralidade de poder de mode federativo, diluindo nacionalidades e relacionando-se com ong's, segundo os processos de privatização de negócios e serviços. (Passetti, 2003, p. 148)

Baseado em Foucault, Passetti afirma que a ecopolítica tem como alvo o planeta e os vivos dentro dele, ou seja, "os produtivos e os que os legitimam políticamente". A biopolítica da população nacional cede espaço a esta ecopolítica de proteção planetária. Mais do que a defesa da sociedade, está a defesa do planeta. Talvez a sociedade só esteja protegida, se o planeta estiver protegido. O corpo-máquina e o corpo espécie só estarão protegidos se o corpo de planeta estiver protegido, e vice-versa.

Portanto, a concepção político-pedagógica da educação ambiental e a articulação das ações educativas devem estar atreladas à proteção e à defesa do planeta. Essa proteção implica em identificar as causas e os responsáveis pelas ameaças à vida da Terra. E, consequentemente, aos humanos, como espécie e como indivíduos. Consiste também em dualizar a problemática ecológica, promovendo uma nova perspectiva unívoca e totalizante a respeito de meio ambiente, que desqualifica as outras que não se encaixam na noção hegemônica institucionalizada. Isto está evidenciado no Programa Nacional de Formação de Educadores Ambientais (PROFEA, 2006), quando sugere o estabelecimento de um novo senso comum:

De um modo inequívoco, tal processo se estina a todos os brasileiros e brasileiras; e tem o ousado intento de promover uma ampla requalificação do senso comum sobre a educação ambiental, pautado hoje numa perspectiva explicativa das ciências naturais e eu uma perspectiva punitiva e prescritiva. Um novo senso comum relativo à educação ambiental pretende aproximá-la do cotidiano das pessoas, dos coletivos, da necessidade de transformar as relações sociais e os mecanismos degradadores do meio ambiente. (BRASIL, 2006, p. 9)

Essa "requalificação" de todo o senso comum relativo à educação ambiental, taxado de explicativo, punitivo e prescritivo demonstra a intenção de legitimar um determinado e novo senso comum. A idéia do documento do Órgão Gestor da Política Nacional de Educação Ambien- 
tal é dar a tudo o que foi produzido antes e além das referências utilizadas na produção do marco teórico governamental da educação ambiental um teor amador e ultrapassado. Aliás, o documento uniformiza e indiferencia tudo o que foi produzido fora das referências oficiais, dicotomizando as teorias em uma que é ultrapassada, prescritivo-explicativa e punitiva, e a outra que é moderna, transformadora e emancipadora.

Além disso, esse estabelecimento de um novo senso comum, por mais democrático, participativo e aberto que possa parecer, é determinado a partir de um seletivo conjunto de saberes e poderes que foram devidamente assimilados pela governamentalidade e, de antigas resistências que, ao ganhar força, passaram a ser outro dispositivo desse poder.

É preciso lembrar aqui que a questão ambiental e, consequentemente, a educação ambiental, surgiram de relações de força e de poder que tentavam fugir ao disciplinamento e ao controle das sociedades das décadas de 50 e 60 . Tiveram para isso que utilizar de um teor libertário extremamente radical, que tinham em sua ação e seu pensamento uma multiplicidade que não foi compreendida e assimilada no momento em que surgiram, sendo intensamente combatidas e desprezadas.

É necessário registrar aqui que até o conceito de educação libertária tenta ser normalizado e cristalizado no próprio PROFEA (pg. 11-12). Ao interpretar e difundir de maneira distorcida $\mathrm{o}$ pensamento e o trabalho de Paulo Freire, encarando o pensamento libertário sob uma perspectiva democrática, as propostas governamentais tentam enquadrar uma noção tão cara a um pensamento de um movimento social completamente alheio e contrário à governamentalização do Estado, e até sua própria existência. É equívoco supor uma prática libertária submetida às avaliações, monitoramentos e controles sob os auspícios de uma política oficializada, que tem como objetivos a articulação e o domínio sobre as práticas educativas ecológicas.

Cabe lembrar que, apesar de sugerir uma ação a partir do princípio da ampla e irrestrita democratização radical da sociedade e superação das desigualdades socioeconômicas do país, o documento do Profea afirma que somente as instituições e pessoas comprometidas com a educação ambiental, e que se articulam para isso é que podem lhe garantir a permanência. Sendo, necessário para isso, o controle social do Estado. Ou seja, a partir dessa perspectiva somente há democracia e participação se as instituições governamentais as promoverem ou permitirem.

Os ambientalismos e a própria educação ambiental foram dragados de maneira rápida e brutal, tornando-se mecanismos de poder que, ao contrário do que sugeria Castoriadis (2006), da ecologia como inserida em um projeto político democrático radical, são justamente instrumentos de dominação de regimes autoritários - sejam eles militares ou burocratizados - impondo restrições a populações apavoradas perante a iminente catástrofe ecológica.

Por sua vez, Alexandre (2003) afirma que a institucionalização e a multissetorialização da ecologia, faz com que mercados e os governos se utilizem dela de uma maneira que se pense os problemas ambientais sem ligação direta com os modelos de desenvolvimento econômico, ou a construção de valores sociais, de forma que seu isolamento e sua banalização façam com que o teor radical dos discursos e ações dos movimentos ecológicos percam força e capacidade de transformação.

Reigota relaciona e enfatiza essa perda de radicalidade de boa parte dos movimentos ecológicos brasileiros com o processo de institucionalização brasileira dos últimos anos, e, consequentemente, com o esfacelamento da cidadania. Principalmente quando se observa entre os agentes responsáveis por esse processo, o "pragmatismo do poder passageiro e pelos benefícios do capital simbólico oferecido pelo aparelho do Estado, dos patrocínios das empresas estatais, das agências de publicidade e dos cofres públicos" (Reigota, 2008). Pragmatismo e benefícios gerados a partir da promoção da homogeneização de um determinado ideário político na construção da política oficial de Educação Ambiental, e o obscurecimento das outras vertentes não aliadas à oficialidade.

Portanto, ao perder sua radicalidade em nome de uma governamentalidade e do próprio estabelecimento de um novo, único e indiferenciado senso comum, a educação ambiental corre o risco de se tornar uma aliada da destruição ecológica que tanto almejava combater. Seja por seu silêncio, seja por suas práticas hierarquizantes, classificatórias e excludentes de conhecimentos e práticas.

\section{RESISTÊNCIAS}

Como resistir, portanto, a essa sujeição dos conhecimentos, práticas, valores e ações no pensar e fazer educação ambiental? Como impedir 
e escapar a esses dispositivos e mecanismos de poder que tentam engessar e retirar a todo custo a potencialidade de constante modificação, diversificação e criação?

Para Foucault (1988), entender as resistências consiste em analisar o poder através do antagonismo de estratégias, pois não se luta contra o poder em si, já que ele não existe como um substantivo, mas se combate os efeitos de poder e o controle que ele estabelece. Por isso mesmo que não existe um inimigo comum e principal, mas sim, inimigos imediatos. Foucault dez que as resistências são lutas anarquistas, pois não esperam solucionar os problemas de um futuro preciso, definido de antemão, seja ele utópico ou catastrófico.

Além disso, essas resistências estão contra o governo da individualização, ou seja, afrimam uma singularidade e uma multiplicidade criadas não sob uma pedagogização ou uma sujeição, mas a partir de uma construção daquilo que se é. E chegar a ser o que se é implica uma prática de resistência aos mecanismos que constroem o sujeito a partir do que o Estado quer que ele seja. São resistências que giram em torno da pergunta "o que somos nós?".

Foucault afirma que essas lutas são um rechaço à inquisição científica e administrativa que determina o que é o que, quem é quem, ou seja, os efeitos do poder ligados ao conhecimento, à competência e à qualificação. Em suma, as resistências lutam também contra os privilégios do conhecimento.

Não existe, para Foucault, um lugar da grande recusa, como uma alma da "rebeldia ou um quartel general do espírito rebelde", mas elas são plurais, casos únicos:

...possíveis, necessárias, improváveis, espontâneas, selvagens, solitárias, planejadas, arrastadas, violentas, irreconciliáveis, prontas ao compromisso, interessadas ou fadadas ao sacrifício. (Foucault, 1988, p. 91)

Elas não existem a não ser no campo específico das relações de poder, não sendo meros subprodutos dessas, mas sim, o outro termo do poder:

Grandes rupturas radicais, divisões binárias e maciças? Às vezes. É mais comum, entretanto, serem pontos de resistência móveis e transitórios, que introduzem na sociedade clivagens que se deslocam, rompem unidades e suscitam reagrupamentos, percorrem os próprio indivíduos, recortando-os e os remodelando, traçando neles, em seus corpos e almas, regiões irredutíveis. (ibidem, p. 92)

Além de ser entendidas como instrumentos e mecanismos de poder, a ecologia e, conseqüentemente, a educação ambiental, podem ser consideradas também como acontecimentos múltiplos e singulares ao mesmo tempo. Surgiram a partir de uma contextualização onde a governamentalização provocava e ampliava a problemática ecológica, e assim, formavam as mais diferentes reivindicações e bloqueios perante as relações de poder então instituídas. Como forma de controlar essas iniciativas e tomar para si a questão, o estado acabou institucionalizando a questão ecológica, transformado-a em ferramenta de regulamentação e normalização. Em anatomopolítica, em biopolítica, em ecopolítica.

Perante essa ecologia do controle, que Godoy (2008) chamou de maior, que se quer holista e integral, como sonho de uma sociedade futura, ideal, limpa, sustentável, e cujo aparato tecnológico e pedagógico continua se desenvolvendo e aperfeiçoando, talvez seja necessário pensar outras educações ambientais, como a perspectiva de ecologias de resistência. Talvez uma ecologia menor, que impeça a perspectiva maior de tornar a ecologia uma nova forma de fascismo burocratizado, regulamentador e controlador.

Perante uma educação ambiental do controle, cujo interesse está intrinsecamente ligado a perspectiva de ação biopolítica, que tem como princípio produzir uma vida a partir da ecologia, cria-se a possibilidade de pensar em educações ambientais que, como sugere Godoy, se mantenham criadoras de novas e múltiplas ecologias a partir da vida.

Ao invés de se tentar trocar um senso comum para estabelecer um outro, cujo princípio se dê apenas como conservador e protetor da vida, talvez seja necessário educar a golpes de martelo, estilhaçando qualquer tentativa de consenso e estabelecimento de formas de pensar e fazer homogêneas, cuja intenção é justamente a cristalização dos saberes, a hierarquização do conhecimento e a uniformização das práticas.

Apesar dos discursos oficiais tentarem demonstrar uma certa abertura ao diálogo, o compromisso com a participação e a democracia, o incentivo a pluralidade e a multiplicidade, o desejo de uma prática transversal, sabe-se que a partir do momento em que ela torna-se uma Política 
Nacional institucionalizada, com uma série de conhecimentos e saberes que se tornam privilegiados nos momentos de tomadas de decisões, na distribuição dos recursos, na ocupação dos postos estratégicos e de trabalho público, privado e de terceiro setor, na aceitação de projetos e trabalhos de pesquisa em eventos dos mais diversos níveis.

Além disso, a própria educação ambiental vem perdendo um momento importante e crucial que diz respeito à sua exposição e submissão no meio científico. Cada vez mais ela se enquadra em moldes reguladores e normalizadores - cada vez mais capilarizados e detalhados - para adquirir um determinado status científico.

Mas as educações ambientais não precisam se tornar normalizadoras, excludentes, controladoras, reguladoras, maiores, para ser científicas. Se a ciência não precisa ser um aparato de estado, maior, exercício de poder, para ser ciência, podendo ser ela resistente, nômade, menor, como já mostraram Deleuze e Guattari (1997) em Tratado de Nomadologia e, de certa forma, Paul Feyerabend (1977), a educação ambiental também pode. Depende da postura na qual elas se apresentam perante as relações de poder e a governamentalização do estado.

Resistir ao poder e os seus devidos encantos, como afirma Nietzsche na epígrafe deste trabalho, é uma arte de viver contrária a todos os tipos de fascismos, os quais, de acordo com Foucault (2010) estão "já instalados ou próximos do ser". Aliás, o próprio Foucault sugeria que a ação política não precisa dar à prática política um valor de verdade, e sim, pode a potencializar como uma força criadora e intensificadora de pensamento. E também, dando aqui o devido deslocamento, de ecologias.

Mais do que estabelecer um corpo paranóico unitário e totalizante, buscando ainda legitimar a ecologia, dando a ela um status de eterna verdade, talvez possamos pensá-la em quebrá-la em milhões de pedaços e esquecer que ela tem uma unidade. A resistência, como prática e pensamento na educação ambiental, sugere "descologizar" a ecologia, para que outras múltiplas e diferenciadas ecologias possam ser inventadas e liberadas, de forma a impedir e bloquear sua cristalização e sedentarização, promovendo e ampliando sua potência radical de transformação e criação.

\section{REFERENCIAS}

ALEXANDRE, A. F. A perda da radicalidade do movimento ambientalista brasileiro: uma nova contribuição à crítica do movimento. Ambiente \& Edu- cação. Rio Grande: Fundação Universidade Federal do Rio Grande, v. 8, n. 1, 2003. P. 73-94.

. Ambientalistas hegemônicos e ambientalistas contra-hegemônicos. Ambiente Hoje. Belo Horizonte, 23 jun. 2010. Disponível em: <http://www. amda.org.br/detalhe/2,40,1190,ambientalistas-hegemonicos-e-mbientalistas-contra-hegemonicos.aspx $>$. Acesso em 07/07/2010.

BRASIL. Decreto $\mathrm{n}^{\circ} 4.281$, de 25 de junho de 2002. Regulamenta a Lei $\mathrm{n}^{\circ} 9.795$, de 27 de abril de 1999, que institui a Política Nacional de Educação Ambiental, e dá outras providências. Diário Oficial [da República Federativa do Brasil], Brasília, DF, v. 139, n. 121, 26 jun. 2002, seção 1, p. 13

. Lei $\mathrm{n}^{\circ} 9.795$, de 27 de abril de 1999. Dispõe sobre a educação ambiental, institui a Política Nacional de Educação Ambiental e dá outras providências. Diário Oficial [da República Federativa do Brasil], Brasília, DF, v. 137, n. 79, 28 abr. 1999, seção 1, p. 1-3.

BRASIL. Órgão Gestor da Política Nacional de Educação Ambiental. Programa Nacional de Educação Ambiental (ProNEA). Brasília: Edições MMA, $3^{a}$ edição, 2005.

. Portfólio Órgão Gestor da Política Nacional de Educação Ambiental. Brasília: Ministério do Meio Ambiente, 2006. Série Documentos Técnicos 7.

Programa Nacional de Formação de

Educadoras(es) Ambientais: por um Brasil educado e educando ambientalmente para a sustentabilidade (ProFEA). Brasília: 2006. Série Documentos Técnicos, n. 8.

CASTORIADIS, Cornelius. Uma sociedade à deriva: entrevistas e debates, 1974-1997. Trad. Claudia Berliner. Aparecida, SP: Idéias e Letras, 2006.

DELEUZE, Gilles. Conversações. Trad. Peter Pál Pelbart. Rio de Janeiro: Ed. 34, 1992.

. Foucault. Trad. Claudia Sant'Anna Martins. São Paulo: Brasiliense, 2006.

DELEUZE, G.; GUATTARI, F. Kafka - Por uma literatura menor. Trad. Julio Castañon Guimarães. Rio de Janeiro: Imago, 1977.

. Mil Platôs: Capitalismo e Esquizofrenia, vol. 
5. São Paulo: Editora 34, 1997. (Coleção Trans.)

FEYERABEND, Paul. Contra o método. Trad. Octanny S. da Mota Leonidas Hegenberg. Rio de Janeiro: Francisco Alves, 1977.

FOUCAULT, Michel. Microfísica do poder. Organização e tradução de Roberto Machado. Rio de Janeiro: Edições Graal, 1979.

Vigiar e punir. Trad. Raquel Ramalhete. $23^{a}$ ed. Petrópolis: Vozes, 1987.

Historia da sexualidade I: a vontade de saber. Trad. José Augusto Guilhom Albuquerque e Maria Thereza da Costa Albuquerque. Rio de Janeiro: Edições Graal, 1988.

Em defesa da sociedade: curso no College de France (1975-1976). Trad. Maria Ermantina Galvão. São Paulo: Martins Fontes, 1999.

Prefácio ao anti-Édipo. (Introdução a uma vida não fascista). In: FOUCAULT, Michel. Ditos e escritos. Repensar a Política. MOTTA, Manoel Barros da (Org.). Tradução de Ana Lúcia Paranhos Pessoa. Rio de Janeiro: Forense Universitária, 2010, v.6. P. 103-106.

GODOY, Ana. A menor das ecologias. São Paulo: Edusp, 2008.

GUATTARI, Felix. As três ecologias. Trad. Maria Cristina F. Bittencourt. Campinas: Papirus, 1990.

Caosmose: um novo paradigma estético. Trad. Ana Lúcia de Oliveira e Lúcia Cláudia Leão. São Paulo: Ed. 34, 1992

PASSETTI, Edson. Anarquismos e sociedade de controle. São Paulo: Cortez, 2003.

REIGOTA, Marcos. Ecologistas. Santa Cruz do Sul: Edunisc, 1999a.

. A floresta e a escola: por uma educação ambiental pós-moderna. São Paulo: Cortez, 1999 b.

Cidadania e educação ambiental. Psicol.

Soc., Porto Alegre, v. 20, n. spe., 2008. Disponível em: <http://www.scielo.br/scielo.php?script=sci arttext\& pid $=$ S010271822008000400009\&lng $=$ pt\&nr $\mathrm{m}=$ iso $>$. Acesso em: $06 \mathrm{dez} .2009$. 